\title{
The sensitization characteristics of adult Chinese patients diagnosed with chronic respiratory diseases
}

\author{
Haisheng Hu, Huimin Huang, Peiyan Zheng, Lu Li, Chuanxu Cai, Ning Li, Baoqing Sun
}

\begin{abstract}
Background: The prevalence of allergen-induced chronic respiratory disease (CRD) is increasing annually.

Objective: This study aimed to analyze the sensitization characteristics of adult Chinese CRD patients.

Methods: The serum specific immunoglobulin E (sIgE) was detected via an inhalation allergy screening test. Total immunoglobulin E (tIgE) levels were measured in 85 asthma patients, 98 chronic obstructive pulmonary disease (COPD) patients, and 69 patients with other CRDs.
\end{abstract}

Results: The total positive rate of allergy screening among CRD patients was $36.1 \%$. Asthma showed the highest rate (45.9\%), followed by COPD (32.7\%) and other CRDs (29.0\%). The positive rate of inhalation allergy screening was significantly higher among office staff (68.9\%) than among outdoor workers $(42.8 \%)$ and farmers $(25.0 \%, P<0.05)$. In patients with COPD, atopy was a risk factor for dyspnea (Odds ratio $=1.22 ; P<0.05$ ). Optimal scaling analysis revealed a correlation between tIgE levels and smoking index (Cronbach's alpha $=91.1 \%)$. Up to $35.0 \%$ of GOLD III or IV patients showed low sIgE and high tIgE.

Conclusion: Patients with CRD had high sensitization. Asthma patients who work indoors were more susceptible to allergies. Atopy was associated with COPD pulmonary function. It is necessary to initially screen the sensitization situation of CRD patients.

Key words: atopy, chronic respiratory disease, Phadiatop test, specific immunoglobulin E, total immunoglobulin E, allergen

\section{From:}

State Key Laboratory of Respiratory Disease, National Clinical Research Center of Respiratory Disease, Guangzhou Institute of Respiratory Health, First Affiliated Hospital of Guangzhou Medical University, Guangzhou 510120, Guangdong, China

\section{Corresponding author:}

Baoqing Sun

151 Yanjiangxi Road, Guangzhou, Guangdong, China

E-mail: sunbaoqing@vip.163.com

\section{Introduction}

With the development of urbanization and worsening air quality, the morbidity of chronic respiratory disease (CRD) has increased annually; in the $21^{\text {st }}$ century, this major disease affects patients' quality of life globally and causes heavy societal burden. ${ }^{1}$ A 2007 World Health Organization survey showed that $>1$ billion people worldwide have CRD, which includes $>300$ million patients with asthma, > 200 million patients with chronic obstructive pulmonary disease (COPD), and > 50 million patients with other types of $\mathrm{CRD}^{2}$ A recent European survey revealed that asthma treatment costs $\$ 22.4$ billion annually. ${ }^{3}$ Another study revealed that the projected cost of COPD in the United States in 2010 was approximately $\$ 50.0$ billion. ${ }^{4}$ Air pollution, smoking, and particularly allergens are risk factors for the onset or aggravation of CRD. ${ }^{5}$ Approximately $18 \%$ COPD patients are atopic, ${ }^{6}$ and fungal sensitization is more likely to cause bronchiectasis in COPD patients. ${ }^{7}$ In contrast, allergens comprise risk factors for asthma. ${ }^{8}$ Therefore, it is important to determine the sensitization profile of patients with CRD. In China, allergy screening has been ignored for a long time. It is difficult to choose a suitable strategy to screen allergies. This factor has resulted in a lack of clinical data regarding allergy screening in adult patients in China, which has a vast territory and large population. ${ }^{9}$ We speculate that in China, the sensitization characteristics of CRD patients may differ among patient populations, as well as among types of CRDs. 
Inhalant allergens have an important role in respiratory allergies, and the inhalant allergy screening test Phadiatop (Phadia, Uppsala, Sweden) gathers most common inhalant allergens into an "ImmunoCAP" (CAP) and requires only one test to determine whether a patient is allergic to common inhalant allergens. ${ }^{10}$ However, an increased total serum $\operatorname{IgE}$ (tIgE) level is a common characteristic in people with atopic disorders. Therefore, we administered the Phadiatop test and the tIgE test on Chinese patients with CRD to explore the sensitization characteristics in CRD patients and the diagnostic value of allergy screening.

\section{Methods}

This study was reviewed and approved by the ethics committee of First affiliated hospital of Guangzhou Medical University, with approval number: GYFYY-2016-73. The use of human serum samples was in accordance with legislation in China and the wishes of donors, their legal guardians or next of kin, where applicable, who had offered written informed consent to using the serum samples for future unspecified research purposes.

\section{Design and patients}

This cross-sectional study included 252 adult patients (i.e., > 18 years old) with CRD. Their data were obtained from Allergy Information Repository of State Key Laboratory of Respiratory Disease (AIR-SKLRD) from January 2017 to December 2017 in China. Patients who were included had (i) recurrent wheezing, chronic cough, or limited pulmonary ventilation and (ii) respiratory physician-confirmed CRD [i.e., asthma (85 patients), COPD (98 patients), and other CRDs (69 patients)]. Patients were excluded if they were undergoing immunotherapy or had parasitic infection, food allergy, or other autoimmune diseases. The patients' sex, age, occupation, questionnaire information (including Modified Medical Research Council Dyspnea Scale [mMRC], and COPD Assessment Test, etc.) and pulmonary function test results [forced vital capacity (FVC), forced expiratory volume in 1 second (FEV1), FEV1 percent predicted (FEV1\% pred), and FVC percent predicted (FVC\% pred)] were collected. There were no significant differences in age and sex among all groups (Table 1).

Table 1. Basic information of 252 patients with chronic respiratory disease

\begin{tabular}{|c|c|}
\hline Clinical characteristics & CRD \\
\hline Total number & 252 \\
\hline Age (y) & $55.9 \pm 18.8$ \\
\hline Sex (male/female) & $150 / 102$ \\
\hline \multicolumn{2}{|l|}{ Diseases } \\
\hline Asthma (N) & $85 / 252$ \\
\hline Smoker (n/N, \%) & $12 / 85,14.1 \%$ \\
\hline \multicolumn{2}{|l|}{$\underline{\text { Severity }}$} \\
\hline Mild/moderate (n/N, \%) & $28 / 85,32.9 \%$ \\
\hline Severe $(\mathrm{n} / \mathrm{N}, \%)$ & $57 / 85,67.1 \%$ \\
\hline \multicolumn{2}{|l|}{$\underline{\text { Occupation }}$} \\
\hline Outdoor worker (n/N, \%) & $28 / 85,32.9 \%$ \\
\hline Office staff (n/N, \%) & $29 / 85,34.2 \%$ \\
\hline Farmer (n/N, \%) & $28 / 85,32.9 \%$ \\
\hline$C O P D(N)$ & $98 / 252$ \\
\hline \multicolumn{2}{|l|}{ Severity } \\
\hline GOLD I II (n/N, \%) & $18 / 98,18.4 \%$ \\
\hline GOLD III IV (n/N, \%) & $80 / 98,81.6 \%$ \\
\hline \multicolumn{2}{|l|}{$\underline{\text { Basic information }}$} \\
\hline Recurrent exacerbation (n/N, \%) & $29 / 98,29.6 \%$ \\
\hline Smoker (n/N, \%) & $68 / 70,88.6 \%$ \\
\hline Quit smoking (n/N, \%) & $30 / 62,48.4 \%$ \\
\hline Smoking index (pack-year) & $600(400,1000)$ \\
\hline
\end{tabular}

Clinical characteristics

CRD

Diseases (Continued)

$\underline{B M I}$

$$
\leq 18.5
$$

$21 / 73,28.8 \%$

$\geq 25.0$

$14 / 73,19.2 \%$

Pulmonary function

FVC (L)

$2.41(1.97,2.93)$

FEV1 (L)

$0.87(0.70,1.17)$

FVC\% pred

$71.70(60.30,79.55)$

FEV1\% pred

$35.80(27.45,40.80)$

Questionnaire score

CAT

$\begin{array}{ll}\leq 10 & 45 / 73,61.6 \% \\ \geq 10 & 28 / 73,38.4 \%\end{array}$

mMRC

0

$5 / 73,6.8 \%$

1

$45 / 73,61.7 \%$

2

$17 / 73,23.3 \%$

3

6/73. $8.2 \%$

4

$0 / 73,0.0 \%$

Other $C R D(N)$

$69 / 252$

FEV1 $=$ forced expiratory volume in one second; FVC = forced vital capacity; CAT $=$ COPD assessment test $;$ mMRC $=$ Modified Medical Research Council Dyspnea Scale for COPD; BMI = body mass index; smoking index $=$ the number of years of smoking $x$ the number of cigarettes smoked per day. 


\section{Diagnosis of disease}

Bronchial asthma was diagnosed using Global Strategy for Asthma Management and Prevention (GINA) guidelines. ${ }^{11} \mathrm{Se}-$ vere asthma was defined by a clinical history of exacerbations, control situation, symptom severity within the previous 12 months, and receiving treatment with medium- or high-dose inhaled corticosteroids (ICS) and additional controller medications.

COPD was diagnosed using Guidelines for the Diagnosis and Treatment of Chronic Obstructive Pulmonary Disease ${ }^{12}$ (i.e., evidence of irreversible obstructive impairment on spirometry, as defined by a postbronchodilator FEV1/FVC < $70 \%)$. Patients who exhibited FEV1\% pred of $\geq 80,50-79$, 30-49, and < 30 were classified as GOLD I, GOLD II, GOLD III, and GOLD IV respectively. In addition, for the purpose of this study, COPD patients with an $\mathrm{mMRC}$ value $\geq 2$ exhibited exertional dyspnea, and patients with a CAT score $\geq 10$ exhibited severe symptoms, patients with a history of acute attacks leading to hospitalization exhibited recurrent exacerbation.

\section{Sample collection and experiment}

Patient samples were obtained from the serum bank of the AIR-SKLRD. Within 2 days after the patients' first presentation and before they received any prescriptions, $5 \mathrm{~mL}$ venous blood was taken and centrifuged at $3000 \mathrm{~g}$ for 10 minutes to prepare the supernatant. It was then stored at $-80^{\circ} \mathrm{C}$. In this study, the Phadiatop sIgE (including fungi, pollens, insects and dust mites) and tgE levels of the serum samples of the 252 patients with CRD were tested with the Phadia 1000 automatic allergy analyzer (ThermoFisher, Uppsala, Sweden) for in vitro diagnostic use. Samples with a Phadiatop sIgE concentration $\geq 0.35 \mathrm{kU} / \mathrm{L}$ were positive.

\section{Data analysis}

Data were processed using SPSS 20.0 statistical software (IBM Corp, Armonk, NY, USA). Normal measurement data such as age are expressed as the mean \pm the standard deviation. Non-normal measurement data such as the FVC level are expressed as the median $(25 \%, 75 \%$ range). The MannWhitney $U$ test was applied to compare two-group differences and the Kruskal-Wallis test was used to compare multigroup differences. Enumeration data are expressed as the percentage. Intergroup differences were compared using the chi-square test $\left(\chi^{2}\right)$ or Fisher's exact test. Odds ratios (OR, 95\% Cl) were conducted for each potential risk factor. Optimal scaling was conducted with categorical principle component analysis. Spearman rank correlation analyses were performed for correlation. A $P$ value $<0.05$ was significant.

\section{Results}

Analysis of the overall profile of adult patients with CRD

The total positive rate of Phadiatop among Chinese adult patients with CRD was $36.1 \%$, and asthma patients comprised the highest proportion (45.9\%), followed by COPD patients (32.7\%) and patients with other CRDs (29.0\%). No significant sex difference existed in the Phadiatop-positive rate and the tIgE level in patients with CRD. The tIgE level was significantly higher in COPD patients [372.00 kU/L $(109.50,141.90)]$ than in asthma patients $[132.30 \mathrm{kU} / \mathrm{L}(54.20,348.00)]$ and in patients with other CRDs [59.80 kU/L $(25.75,136.50)]$ (Kruskal-Wallis $=50.3, P<0.001)($ Table 2$)$.

Table 2. Phadiatop-positive distribution of 252 patients with chronic respiratory disease

\begin{tabular}{|c|c|c|c|}
\hline Characteristic & Asthma & COPD & Other CRD \\
\hline Total number & 85 & 98 & 69 \\
\hline Age (y) & $53.1 \pm 10.9$ & $64.3 \pm 18.8$ & $47.3 \pm 16.3$ \\
\hline $\operatorname{TIgE}(\mathrm{kU} / \mathrm{L})^{*}$ & $132.30(54.20,348.00)$ & $372.00(109.50,141.90)$ & $59.80(25.75,136.50)$ \\
\hline Phadiatop-positive rate (n, \%) & $39,45.9 \%$ & $32,32.7 \%$ & $20,29.0 \%$ \\
\hline \multicolumn{4}{|l|}{ Phadiatop class $(\mathrm{a} / \mathrm{n}, \%)$} \\
\hline Class 1 & $8 / 39,20.5 \%$ & $14 / 32,43.8 \%$ & $7 / 20,35.0 \%$ \\
\hline Class 2 & $17 / 39,43.6 \%$ & $15 / 32,46.9 \%$ & $4 / 20,20.0 \%$ \\
\hline Class 3 & $3 / 39,7.7 \%$ & $2 / 32,6.3 \%$ & $5 / 20,25.0 \%$ \\
\hline Class 4 & $8 / 39,20.5 \%$ & $1 / 32,3.1 \%$ & $2 / 20,10.0 \%$ \\
\hline Class 5 & $3 / 39,7.7 \%$ & $0 / 32,0 \%$ & $2 / 20,10.0 \%$ \\
\hline Class 6 & $0 / 39,0 \%$ & $0 / 32,0 \%$ & $0 / 20,0 \%$ \\
\hline
\end{tabular}

$\mathrm{COPD}=$ chronic obstructive pulmonary disease; $\mathrm{CRD}=$ chronic respiratory disease; $\operatorname{sIgE}=$ serum immunoglobulin $\mathrm{E} ; \mathrm{tIgE}=$ total immunoglobulin $\mathrm{E}$.

* Information is based on the Kruskal-Wallis test.

The sIgE levels are ranked as Class 0 to Class 6, as follows: Class $0(<0.35 \mathrm{kU} / \mathrm{L})$, Class $1(\geq 0.35$ and $<0.70 \mathrm{kU} / \mathrm{L})$, Class $2(\geq 0.70$ and $<3.50 \mathrm{kU} / \mathrm{L})$, Class 3 ( $\geq$ 3.50 and $<17.50 \mathrm{kU} / \mathrm{L})$, Class $4(\geq 17.50$ and $<50.00 \mathrm{kU} / \mathrm{L})$, Class $5(\geq 50.00$ and $<100.00 \mathrm{kU} / \mathrm{L})$, Class $6(\geq 100.00 \mathrm{kU} / \mathrm{L})$. 


\section{Asthma patients}

The total Phadiatop-positive rate among asthma patients was $45.9 \%$. The Phadiatop-positive rates among patients with mild-to-moderate asthma and with severe asthma were $42.1 \%$ and $53.6 \%$ respectively $(P>0.05)$. The tIgE level was higher in patients with severe asthma $[163.90 \mathrm{kU} / \mathrm{L}(53.50,405.10)]$ than in patients with mild-to-moderate asthma $[113.40 \mathrm{kU} / \mathrm{L}$ (56.58, 187.70)] (Mann-Whitney $U, 485.0 ; P=0.040)$. In addition, the Phadiatop-positive rate was much higher in asthmatic office staff $(68.9 \%)$ than in asthmatic outdoor workers $(42.8 \%)$ and farmers $\left(25.0 \%, \chi^{2}=11.24, P=0.004\right)$. The $\operatorname{tgE}$ level was considerately higher in asthmatic outdoor workers $[196.50 \mathrm{kU} / \mathrm{L}(106.60,520.10)]$ than in asthmatic office staff [125.50 kU/L (49.90, 337.40)] and farmers (84.02 kU/L (35.55, 228.40), Kruskal-Wallis $=7.16, P=0.028)$.

\section{Patients with COPD}

The total Phadiatop-positive rate among COPD patients was $32.7 \%$, and the Phadiatop-positive rates among GOLD I II and GOLD III IV patients were $27.8 \%$ and $37.8 \%$, respectively $(P>0.05)$. The $\operatorname{tgE}$ level was significantly higher in GOLD III IV patients $[466.00 \mathrm{kU} / \mathrm{L}(173.00,1951.00)]$ than in GOLD I II patients [91.20 kU/L $(50.68,257.30)]$ (MannWhitney $U, 309.5 ; P<0.001)$. The Phadiatop-positive rate among patients with recurrent exacerbation of COPD was $42.9 \%$. Atopy maybe a risk factor for dyspnea (OR $=1.22 ; 95 \%$ CI, 0.95-1.75; $P=0.048$ ) (Figure 1). In addition, the FVC levels were lower in atopic COPD patients $[2.06 \mathrm{~L}(1.83,2.61)]$ than in nonatopic patients [2.63 L $(2.10,3.00)]$ (Mann-Whitney $U, 442.5 ; P=0.033$ ) (Figure 2). Optimal scaling analysis revealed a correlation between the tIgE level and smoking index (Cronbach's alpha $=91.1 \%$ ), and a negative correlation between the tIgE level and FVC level $\left(r_{s}=-0.291, P=0.009\right)$.

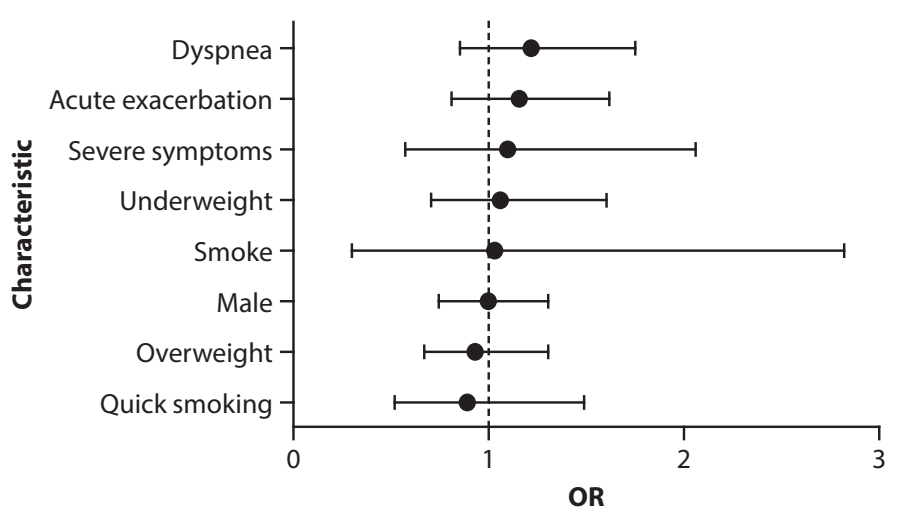

Figure 1. The odds ratio $(\mathrm{OR})$ between atopy and the characteristics of patients with chronic obstructive pulmonary disease (COPD). "Underweight" is a body mass index $(\mathrm{BMI}) \leq 18.5$ and "overweight" is a BMI $\geq 25.0$. Atopy is a risk factor for dyspnea $(\mathrm{OR}=1.22 ; 95 \% \mathrm{CI}, 0.95-1.75 ; P<0.05)$, recurrent exacerbation $(\mathrm{OR}=1.15 ; 95 \%, 0.92-1.62 ; P<0.05)$, and severe symptoms $(\mathrm{OR}$ $=1.10 ; 95 \%$ CI, $0.58-1.02 ; P>0.05)$ in patients with COPD. Quitting smoking $(\mathrm{OR}=0.89,95 \% \mathrm{CI}=0.52$ to $1.49, P>0.05)$ may be a protective factor for atopy.
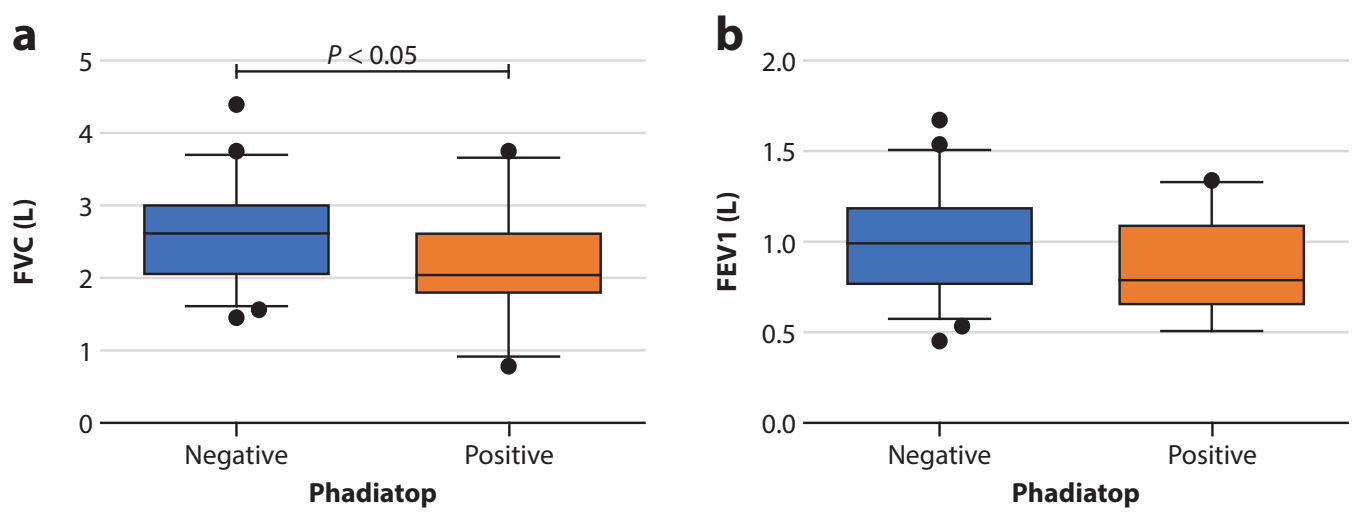

Figure 2. Difference in pulmonary function between chronic obstructive pulmonary disease (COPD) patients with atopy and without atopy. a) Among the 98 COPD patients, Phadiatop-negative patients have higher forced vital capacity (FVC) levels [2.63 L $(2.10,3.00)]$, compared to Phadiatop-positive patients $[2.06 \mathrm{~L}(1.83,2.61)](P<0.05)$. Phadiatop-negative patients have higher pulmonary function, compared to Phadiatop-positive patients. However, the difference is statistically insignificant [as shown in b) $-\mathrm{d})]$.

FEV1 = forced expiratory volume in 1 second; FEV1\% pred = FEV1 percent predicted; FVC = forced vital capacity; FVC\% pred $=$ FVC percent predicted.

* The information is based on the Mann-Whitney $U$ test results. 
C

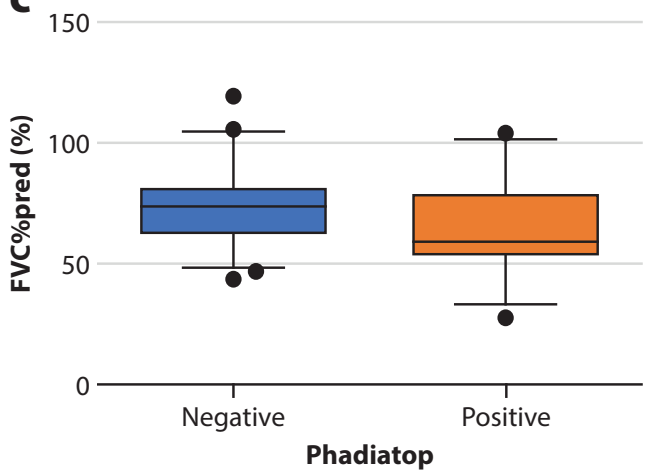

d

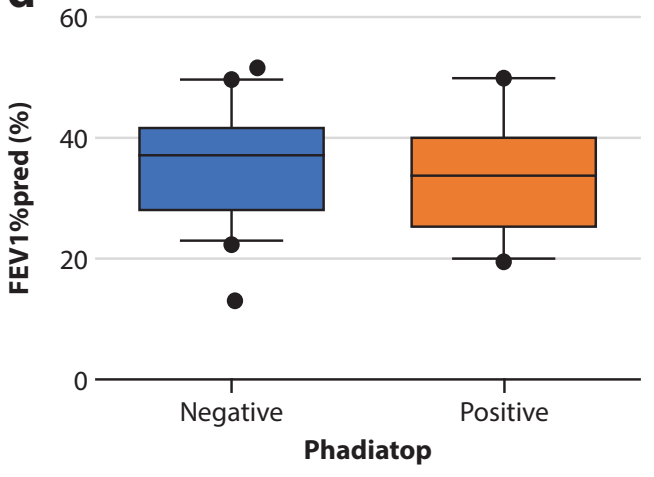

Figure 2. (Continued)

However, no correlation existed between the tIgE level and mMRC value $\left(r_{s}=-0.084, P>0.05\right)$ or CAT score $\left(r_{s}=-0.099\right.$, $P>0.05$ ) (Figure 3), and no correlation existed between the Phadiatop-positive rate and the CAT score.

\section{Correlation between Phadiatop and tIgE level in patients with CRD}

The Spearman analysis revealed that patients with mild-to-moderate asthma had a strong correlation between the levels of tIgE and Phadiatop sIgE $\left(r_{s}=0.709, P<0.001\right)$,

but this correlation was relatively weak in severe asthma patients $\left(r_{s}=0.486, P<0.001\right)$. There was similarly a strong correlation between the level of $\operatorname{tg} \mathrm{E}$ and Phadiatop $\operatorname{sigE}$ in GOLD I II patients (GOLD I II: $r_{\mathrm{s}}=0.798, P<0.001$ and GOLD III IV: $\left.r_{s}=0.483, P<0.001\right)$, and up to $35.0 \%$ of GOLD III IV patients with a low Phadiatop level $(\leq 10$ $\mathrm{kU} / \mathrm{L})$ had a high level of $\operatorname{tgE}(\geq 1000 \mathrm{kU} / \mathrm{L})$ (Figure 4 a, b, c). Approximately $57.1 \%$ of these patients had an mMRC value $\geq 2$, a CAT score $\geq 10$, or recurrent exacerbations (Figure 4d).

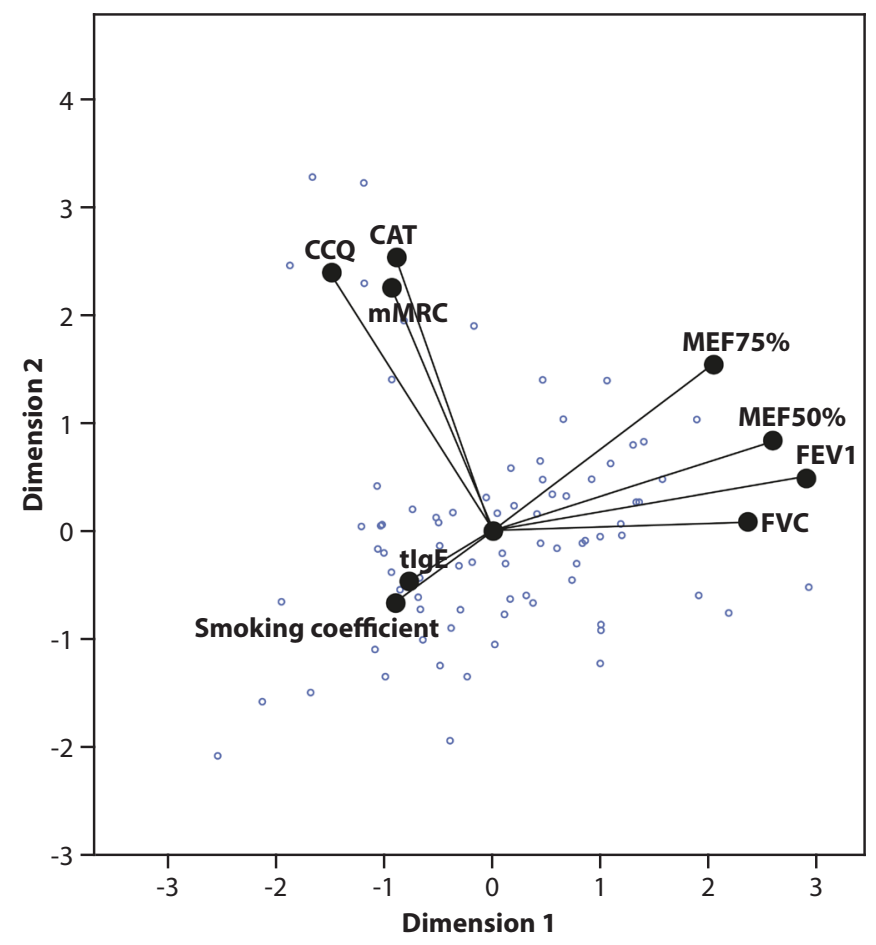

Figure 3. Optimal scaling analysis of tIgE and clinical features in COPD patients. The distance from the point represents their relationship. There is a correlation between the tIgE and smoking index (Cronbach's alpha $=91.1 \%$ ).

$\mathrm{CAT}=$ Chronic Obstructive Pulmonary Disease $(\mathrm{COPD})$ Assessment Test $\mathrm{CCQ}=$ Clinical COPD Questionnaire; FEV1 $=$ forced expiratory volume in 1 second; FVC = forced vital capacity; MEF50\%/75\% = mesoexpiratory flow 50\%/75\%; mMRC = Modified Medical Research Council Dyspnea Scale.

* Information is based on optimal scaling analysis. 
a
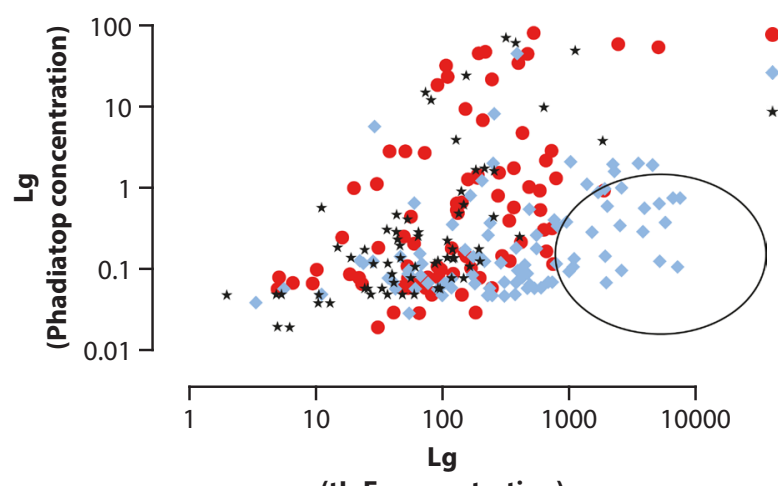

(tlgE concentration)

b

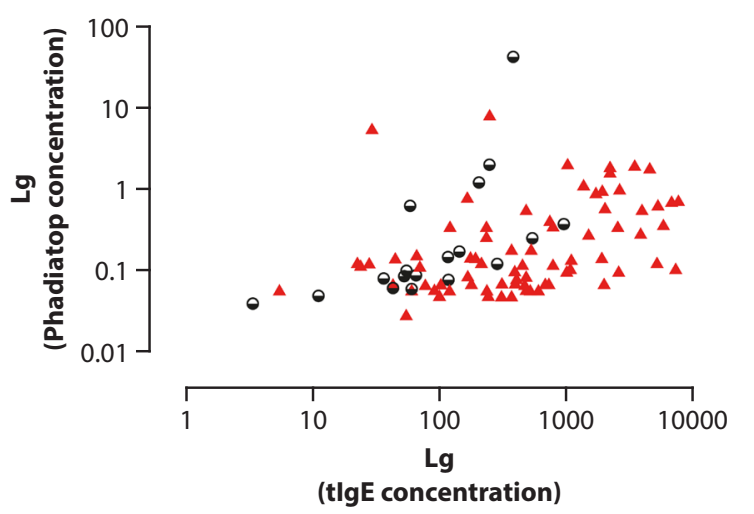

C

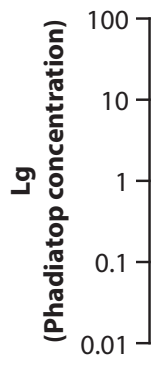

(tlgE concentration) d

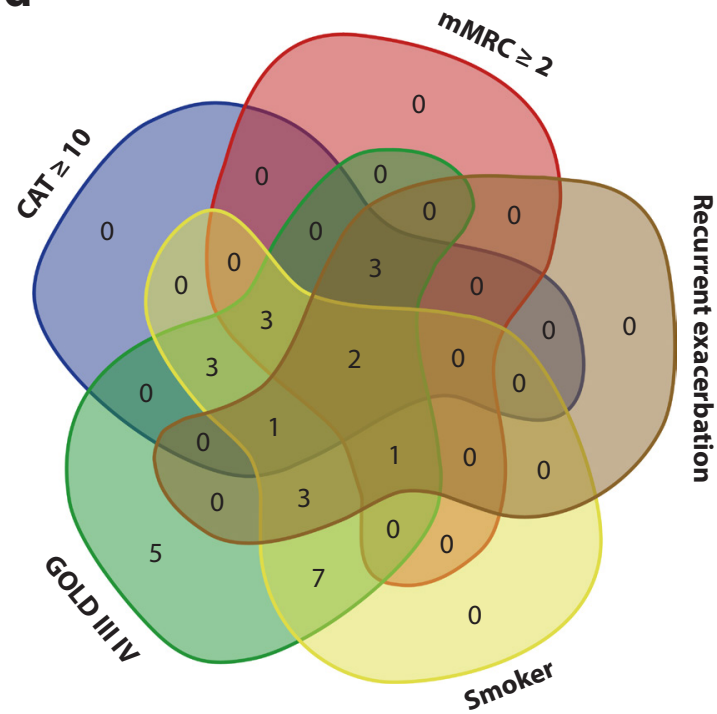

$\triangle$ GOLD III IV O GOLD III
- Asthma

COPD

Other CRD
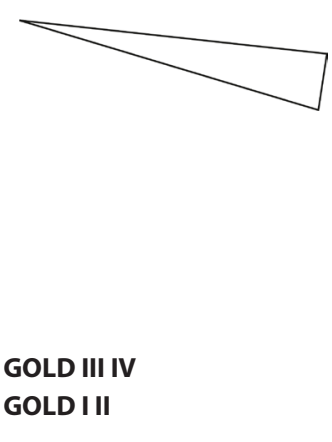

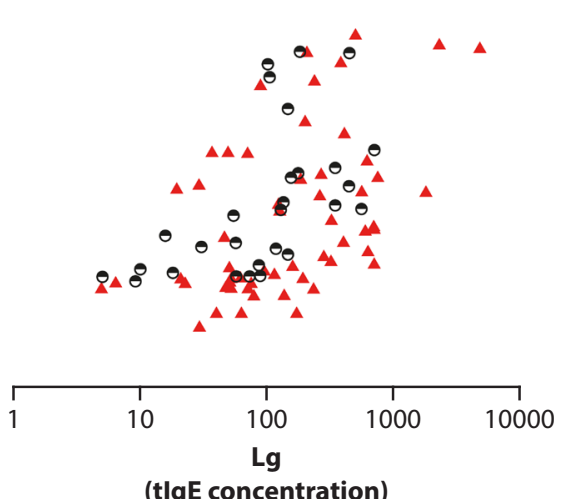

S-asthma

○ M-asthma

(tlgE concentration)

Figure 4. The correlation between Phadiatop and tIgE level in CRD patients

* Spearman rank correlation analyses were performed for the correlation study. The $x$ axis in the graph refers to the logarithm of the tIgE and the $y$ axis refers to the logarithm of the Phadiatop sIgE. a) The level of tIgE and Phadiatop sIgE are correlated $\left(r_{s}\right.$ $=0.451, P<0.001)$ in $252 \mathrm{CRD}$. The circle indicates that $40.5 \%$ of COPD patients with a low Phadiatop level $(\leq 10 \mathrm{kU} / \mathrm{L})$ have a high level of $\operatorname{tg} \mathrm{E}(\geq 1000 \mathrm{kU} / \mathrm{L})$, compared to patients with asthma (1.1\%). b) The correlation between the level of tIgE and Phadiatop sIgE is weaker in GOLD III IV patients $\left(r_{s}=0.483, P<0.001\right)$ than in GOLD I II patients $\left(r_{s}=0.798, P<0.001\right)$. c $)$ The correlation between the level of tIgE and Phadiatop sIgE is weaker in patients with severe asthma $\left(r_{s}=0.486, P<0.001\right)$ than in patients with mild-to-moderate asthma $\left(r_{s}=0.709, P<0.001\right)$. d) Venn diagram of the characteristics of patients with a low Phadiatop level $(\leq 10 \mathrm{kU} / \mathrm{L})$, who exhibit a high level of $\operatorname{tgEE}(\geq 1000 \mathrm{kU} / \mathrm{L})$. A total of $93.3 \%$ of patients had GOLD III IV disease classification.

$\mathrm{COPD}=$ chronic obstructive pulmonary disease; $\mathrm{CRD}=$ chronic respiratory disease; $\mathrm{GOLD}=$ Global Initiative for Chronic Obstructive Lung Disease; $\mathrm{Lg}=\operatorname{logarithm}$ (i.e., $\log _{10}$ ); sIgE = serum immunoglobulin E; tIgE = total immunoglobulin E. 


\section{Discussion}

The present study investigated 252 adult patients with $\mathrm{CRD}$ and found that the total Phadiatop-positive rate was $36.1 \%$, suggesting that sensitization is common in Chinese adult patients with CRD. However, allergy screening has not attracted due attention in China. Especially in basic-level hospitals or rural areas, respiratory allergies tend to be neglected, which leads to worsening symptoms and more severe chronic airway disease. ${ }^{13,14}$ In the future, clinicians should focus on the value of allergy screening in CRD patients.

This study also found that the Phadiatop-positive rate was highest among patients with asthma (45.9\%), and the high tIgE level in patients with severe asthma, compared to patients with mild-to-moderate asthma, suggested atopy and may worsen the condition of asthmatic patients. ${ }^{15}$ A study from the United States similarly showed that patients with severe asthma had higher concentrations of fractional exhaled nitric oxide and significantly greater sensitization to aeroallergens, compared to patients with mild-to-moderate asthma. ${ }^{16}$ However, a review study ${ }^{17}$ examining differences between atopic (i.e., allergic) asthma and nonatopic (i.e., intrinsic) asthma demonstrated that nonatopic asthmatics had a more severe clinical course. However, regardless of the type of asthma, pretreatment allergy screening should be considered.

We found that asthmatic office staff had the highest sensitization (68.9\%), and that the $\operatorname{tg}$ E level was significantly higher in asthmatic office staff than in asthmatic farmers. We speculate the high sensitization may be associated with dust mites, ${ }^{10}$ which are the most predominant allergen in an indoor environment. A study ${ }^{18}$ from Malaysia showed that the Der f 1 allergen protein in dust is a risk factor for "sick building syndrome" in an office environment. Therefore, with the progress in urbanization and the increase of office staff in China, ${ }^{19}$ the morbidity of chronic airway diseases caused by allergens is expected to increase annually. This factor makes allergy screening even more urgent.

In this study, $32.7 \%$ COPD patients had atopy, and the tIgE level was significantly higher in GOLD III IV patients than in GOLD I II patients. This finding illustrates that the atopic situation of patients with COPD cannot be ignored. A study from Brazil also reported that 32.8\% COPD patients presented with a positive skin prick test result. ${ }^{20}$ Our study similarly showed that $42.9 \%$ COPD patients with recurrent exacerbation were atopic, and that atopy maybe a risk factor for dyspnea. A study ${ }^{7}$ of 273 COPD patients similarly showed that COPD patients with increased tIgE levels have a longer history of dyspnea and more serious symptoms than patients without these features. We also found that the FVC levels were lower among atopic COPD patients than among nonatopic COPD patients. A cross-sectional case-control study of 39 COPD patients in Egypt revealed that atopic COPD patients had a longer history of illness, high smoking index, and a lower FEV1. ${ }^{21}$ Therefore, COPD patients also need allergy screening, and atopic COPD patients with severe symptoms can attempt to combine anti-IgE antibody treatment. A study of 64 COPD patients showed a significant correlation between $\operatorname{tgE}$ and the expression of the high-affinity IgE receptor on plasmocytic dendritic cells.
This finding indicates anti-IgE antibody treatment is possible for severe COPD. ${ }^{22}$ It is interesting that the optimal scaling analysis in our study revealed a correlation between the $\operatorname{tgE}$ level and smoking index. Smoking may be a risk factor that increases the tIgE level. A Swiss study also demonstrated that the $\operatorname{tgE}$ level of smoking COPD patients is higher than that of nonsmoking COPD patients ( $39.7 \mathrm{kU} / \mathrm{L}$ vs. $27.2 \mathrm{kU} / \mathrm{L}){ }^{23}$

The present study also demonstrated a weak relationship between $\operatorname{IgE}$ and Phadiatop in severe CRD patients (especially COPD). These results constitute the first detailed report of Chinese adult CRD patients.

Phadiatop only screens for sensitivity to common inhalant allergens, whereas $\operatorname{tgE}$ represents the total $\operatorname{IgE}$ level in the serum. ${ }^{10}$ Therefore, the levels of serum Phadiatop sIgE will not rise if the increased level of IgE in the serum of CRD patients is not caused by common inhalant allergens. Surprisingly, patients with a low Phadiatop level $(\leq 10 \mathrm{kU} / \mathrm{L})$ and a high $\operatorname{tgE}$ level (93.3\%) were classified as GOLD III IV patients. We did not exclude COPD patients with more sensitization to uncommon allergens, but we wish to reconsider the concert of "atopen," which are substances-not necessarily immunogenic themselves-that are capable of deliberately directing $\operatorname{IgE}$ production. ${ }^{24}$ For example, a study showed that diesel exhaust particles can increase local $\operatorname{IgE}$ through altering the relative amounts of five different epsilon-messenger ribonucleic acids (i.e., the code for different IgE proteins) generated by alternative splicing. ${ }^{25}$ Patients with COPD are often exposed to a variety of dust particles in the environment. Therefore, more opportunities exist for individuals to come into contact with atopens such as diesel exhaust particles, and thereby cause tIgE production in the body. Possible implications of this finding for atopen in COPD patients require further investigation. However, the main limitation of this study was its small sample size. A larger sample size will be needed for future study to verify these findings.

\section{Conclusion}

This study showed that, in Chinese adult CRD patients, the rate of atopy is highest among asthma patients (45.9\%), followed by COPD patients $(32.7 \%)$ and patients with other CRDs (29.0\%). The asthmatic patients who work indoors are more susceptible to allergies, and atopy correlated with COPD pulmonary function. In general, the Phadiatop test determines whether a patient is allergic by using only one CAP, which greatly reduces costs and time. However, this method is sometimes insufficient (e.g., for patients with COPD). The allergy screening strategy should consider combining tIgE and Phadiatop sIgE.

\section{Acknowledgements}

We would like to thank Editage [www.editage.cn] for English language editing. Furthermore, we thank everyone involved in the collection, storage, transportation, and management of the serum samples. 


\section{Declaration of Conflicting Interests}

The authors declare that they have no conflict of interest.

\section{Funding}

This study was funded by the National Natural Science Foundation of China (Project No.: 81572063, 81601394), the Medicine and Health Care Technology Projects of Guangzhou (Project No.: 2017A013010017), and the Bureau of Education Projects of Guangzhou (Project No.: 1201630393, 1201630044). The funders had no role in study design, data collection and analysis, decision to publish, or preparation of the manuscript. No additional external funding was received for this study.

\section{Author Contributions}

- B.Q.S. was the group leader and proposed the idea.

- H.S.H and P.Y.Z. wrote the main manuscript text.

- H.S.H. and L.L prepared the figures and tables.

- H.S.H and C.X.C. designed and performed the measurements.

- H.M.H and H.S.H interpreted the experimental data and performed data analysis.

- B.Q.S. and H.S.H wrote the manuscript and reviewed it.

- All authors approve and agree to the final version of the manuscript.

\section{References}

1. Billo NE. Role of the global alliance against respiratory diseases in scaling up management of chronic respiratory diseases-summary meeting report. J Thorac Dis. 2017;9(8):2337-8.

2. Bousquet J, Dahl R, Khaltaev N. Global alliance against chronic respiratory diseases. Allergy. 2007;62(3):216-23.

3. Domínguez-Ortega J, Phillips-Anglés E, Barranco P, Quirce S. Cost -effectiveness of asthma therapy: a comprehensive review. J Asthma. 2015; 52:529-37.

4. Lee J, Lee JH, Kim JA, Rhee CK. Trend of cost and utilization of COPD medication in Korea. Int J Chron Obstruct Pulmon Dis. 2017;12:27-33.

5. Galán I, Simón L, Boldo E, Ortiz C, Fernandez-Cuenca, Linares C, et al. Changes in hospitalizations for chronic respiratory diseases after two successive smoking bans in Spain. PLoS One. 2017;12(5):e0177979.

6. Fattahi F, ten Hacken NH, Löfdahl CG, Hylkema MN, Timens W, Postma DS, et al. Atopy is a risk factor for respiratory symptoms in COPD patients: results from the EUROSCOP study. Respir Res. 2013;14:10.

7. Jin J, Liu X, Sun Y. The prevalence of increased serum IgE and Aspergillus sensitization in patients with COPD and their association with symptoms and lung function. Respir Res. 2014;15:130.
8. Kanchongkittiphon W, Gaffin JM, Phipatanakul W. The indoor environment and inner-city childhood asthma. Asian Pac J Allergy Immunol. 2014;32(2):103-10.

9. Merrett J, Merrett TG. Phadiatop-A novel IgE antibody screening test. Clin Allergy. 1987;17:409-16.

10. Zeng G, Hu H, Zheng P, Wu G, Wei N, Liang X, et al. The practical benefit of Phadiatop test as the first-line in vitro allergen-specific immunoglobulin $\mathrm{E}$ (sIgE) screening of aeroallergens among Chinese asthmatics: a validation study. Annals of Transl Med. 2018; 6:151.

11. Bateman ED, Hurd SS, Barnes PJ, Bousquet J, Drazen JM, FitzGerald $\mathrm{JM}$, et al. Global strategy for asthma management and prevention: GINA executive summary. Eur Respir J. 2008;31:143-78.

12. Bousquet J, Khaltaev N, Cruz AA, Denburg J, Fokkens WJ, Togjas A, et al. Allergic rhinitis and its impact on asthma (ARIA) 2008 update (in collaboration with the World Health Organization, GA(2) LEN and AllerGen). Allergy. 2008;63(Suppl 86):8-160.

13. Linden M, Greiff L, Andersson M, Svensson C, Akerlund A, Bende M, et al. Nasal cytokines in common cold and allergic rhinitis. Clin Exp Allergy. 1995;25:166-72.

14. Scadding GK. Optimal management of allergic rhinitis. Arch Dis Child. 2015;100:576-82

15. Qu J, Li Y, Zhong W, Gao P, Hu C. Recent developments in the role of reactive oxygen species in allergic asthma. J Thorac Dis. 2017;9:E32-43.

16. Fitzpatrick AM, Gaston BM, Erzurum SC, Teague WG; National Institutes of Health/National Heart, Lung, and Blood Institute Severe Asthma Research Program. Features of severe asthma in school-age children: atopy and increased exhaled nitric oxide. J Allergy Clin Immunol. 2006; 118:1218-25.

17. Novak N, Bieber T. Allergic and nonallergic forms of atopic diseases. J Allergy Clin Immunol. 2003;112:252-62.

18. Lim FL, Hashim Z, Md Said S, Than LT, Hashim JH, Norback D. Sick building syndrome (SBS) among office workers in a Malaysian university - associations with atopy, fractional exhaled nitric oxide (FeNO) and the office environment. Sci Total Environ. 2015;536:353-61.

19. D’Amato G, Holgate ST, Pawankar R, Pawankar R, Ledford DK, Cecchi L, et al. Meteorological conditions, climate change, new emerging factors, and asthma and related allergic disorders. A statement of the World Allergy Organization. World Allergy Organ J. 2015;8:1-52

20. Neves MC, Neves YC, Mendes CM, Bastos MN, Camelier AA, Queiroz CF, et al. Evaluation of atopy in patients with COPD. J Bras Pneumol. 2013;39:296-305

21. Samaha HMS, Elsaid AR, NasrEldin E. Total serum IgE level in COPD patients. Egypt J Chest Dis Tuberc. 2015;64:573-7.

22. Stoll P, Baehker A, Ulrich M, Bratke K, Garbe K, Virchow JC, et al Upregulation of the high-affinity IgE receptor on plasmacytoid dendritic cells in severe COPD. Eur Respir J. 2015;46:PA3614.

23. Wuthrich B, Leuenberger P, Ackermann-Liebrich U, Schindler C, Karrer W, Kunzli N, et al. Atopy, air pollution and respiratory diseases in a Swiss normal population (SAPALDIA-Study). Allergologie. 1999;22:267-74.

24. Berrens L. The atopen: a rehabilitation. Ann Allergy. 1976;36:351-61.

25. Diaz-Sanchez D, Dotson AR, Takenaka H, Saxon A. Diesel exhaust particles induce local IgE production in vivo and alter the pattern of IgE messenger RNA isoforms. J Clin Invest. 1994;94:1417-25. 